\title{
Correspondence
}

\section{Early use of sodium nitroprusside in respiratory distress syndrome}

Sir,

The management of respiratory distress syndrome (RDS) with continuous positive airways pressure and intermittent positive pressure ventilation (IPPV) is well established. Sometimes these measures are insufficient to maintain adequate oxygenation. A report from Liverpool (Abbott et al., 1978) described the comparatively late use of sodium nitroprusside in a baby with RDS. We describe the early use of sodium nitroprusside in a baby with severe RDS.

A baby boy, son of a 21-year-old Kenyan-Asian, was born at 28 weeks' gestation and weighed $1 \cdot 1 \mathrm{~kg}$. His mother had been admitted 8 days before delivery with spontaneous rupture of membranes. 24 hours before delivery she had become pyrexial and been treated with cephradine. Dexamethasone and ritodrine were given during labour, and delivery was assisted by Wrigley's forceps. The baby needed IPPV for 15 minutes after birth and rapidly developed severe $\mathrm{RDS}$ which required ventilation within 2 hours of delivery. $\mathrm{PaO}_{2}$ was initially maintained at $10 \mathrm{kPa}(75 \mathrm{mmHg})$, but at 6 hours it had fallen and could not be maintained above $4 \mathrm{kPa}(30$ $\mathrm{mmHg}$ ). At this stage the ventilator settings were: ratio inspired :expired (I:E) $4: 1$, pressures $\mathrm{I}: \mathrm{E} 25 / 5 \mathrm{~cm} \mathrm{H} \mathrm{H}_{2} \mathrm{O}$, $\mathrm{FIO}_{2} 0 \cdot 9$, ventilator rate $40 / \mathrm{min}$.

Sodium bicarbonate infusion ( $2 \mathrm{mmol} / \mathrm{kg}$ per 24 hours) was begun at 4 hours, and sodium nitroprusside $(120 \mu \mathrm{g} /$
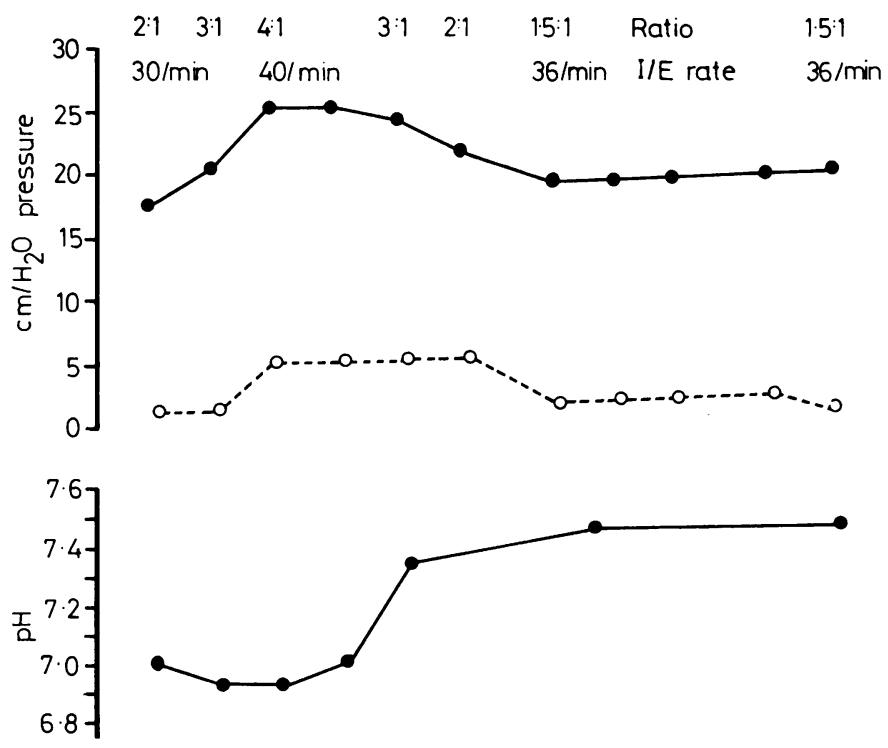

Figure The early use of sodium nitroprusside in respiratory distress syndrome.

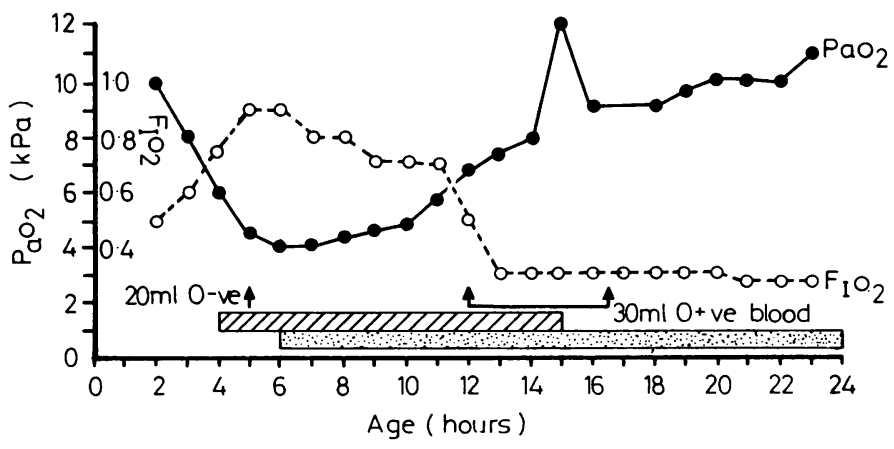

Sodium nitroprusside Sodium bicarbonate $\square$ 
$\mathrm{kg}$ per hour) at 6 hours. Fresh donor blood, total $50 \mathrm{ml}$, was transfused to maintain the systolic blood pressure above $50 \mathrm{mmHg}$. At 8 hours the baby's condition began to improve with an increase in $\mathrm{PaO}_{2}$, and at 15 hours, $\mathrm{PaO}_{2}$ could be maintained at $12 \mathrm{kPa}(90 \mathrm{mmHg})$ with the following ventilator settings: ratio $\mathrm{I}: \mathrm{E} 1 \cdot 5: 1$, pressures I:E $18 / 2 \mathrm{~cm} \mathrm{H}_{2} \mathrm{O}, \mathrm{F}_{10} \mathrm{O} \cdot 3$, ventilator rate $36 / \mathrm{min}$.

The sodium nitroprusside infusion was continued for 24 hours after which time the dose was logarithmically reduced every 12 hours until it was finally stopped at 72 hours. During the next 12 hours the blood pressure rose from $50 / 40$ to $90 / 60 \mathrm{mmHg}$ but it returned to normal 24 hours after discontinuing the infusion. The infant's progress in the first 24 hours of life is shown in the Figure.

The baby continued his difficult neonatal period with a respiratory tract infection on day 5 and a Gramnegative septicaemia on day 14 . He was discharged home on day 56 and to date, at 3 months, shows normal development.

In RDS there is often very pronounced right-to-left shunting (Strang, 1966). Sodium nitroprusside is a directacting vasodilator (Tinker and Michenfelder, 1976) and its action on the pulmonary vascular bed reduces pulmonary vascular resistance, thereby increasing pulmonary blood flow. This decreases right-to-left shunting and results in an increased $\mathrm{PaO}_{2}$.

Compared with the case in Liverpool, we gave sodium nitroprusside at a very early stage in the illness. The fact that this was followed by such a rapid improvement is convincing evidence of its therapeutic value. Thus sodium nitroprusside infusion may have an important role in the management of babies with severe RDS who deteriorate in spite of mechanical ventilation.

Attention has recently been drawn to the possible toxic effects of sodium nitroprusside (British Medical Journal, 1978). Our observation that $50 \mathrm{ml}$ blood (about $57 \%$ of blood volume) was needed to maintain systolic blood pressure indicates that sodium nitroprusside should be used only if there are adequate facilities for biochemical and blood pressure monitoring.

\section{References}

Abbott, T. R., Rees, G. J., Dickinson, D., Reynolds, G., and Lord, D. (1978). Sodium nitroprusside in idiopathic respiratory distress syndrome. British Medical Journal, 1, 1113-1114.

British Medical Journal (1978). Editorial: Controlled intravascular sodium nitroprusside treatment. British Medical Journal, 2, 784-785.

Strang, L. B. (1966). The pulmonary circulation in the respiratory distress syndrome. Pediatric Clinics of North America, 13, 693-701.

Tinker, J. H., and Michenfelder, J. D. (1976). Sodium nitroprusside: pharmacology, toxicology, and therapeutics. Anesthesiology, 45, 340-354.

D. W. Beverley, C. A. Hughes, D. P. Davies, M. J. HARRAN, AND D. A. DuCKer Neonatal Unit, Leicester Royal Infirmary Maternity Hospital, Leicester LE1 5WW

\section{Weaning very low birthweight infants from mechanical ventilation using intermittent mandatory ventilation and theophylline}

Sir,

We read with interest the paper by Barr (Archives, 1978, 53, 598), and should like to report our recent experience with aminophylline in two very low birthweight infants.

\section{Case 1}

This infant born at a gestational age of 30 weeks weighing $1190 \mathrm{~g}$ was severely asphyxiated at birth and required mechanical ventilation for the first 4 days of life. At age 4 weeks, 48 hours after the introduction of nasojejunal feeds, he developed necrotising enterocolitis and required a $40 \mathrm{~cm}$ small bowel resection. At the same time, mechanical ventilation was recommended because of recurrent apnoea and bradycardia: initial ventilator settings were: peak pressure $25 \mathrm{~cm} \mathrm{H}_{2} \mathrm{O}$, positive end expiratory pressure $5 \mathrm{~cm} \mathrm{H}_{2} \mathrm{O}$, and frequency 28 cycles/ min.

During the next 6 days attempts to wean him from the ventilator by decreasing the rate to 16 cycles/min resulted in episodes of bradycardia and cyanosis with the capillary $\mathrm{PCO}_{2}$ increasing from 4.7 to $7.9 \mathrm{kPa}$ (35 to $59 \mathrm{mmHg}$ ). In view of this, aminophylline was administered with a loading dose of $3.3 \mathrm{mg} / \mathrm{kg}$ intravenously followed by a maintenance dose of $3 \mathrm{mg} / \mathrm{kg}$ per day in three divided doses. Serum aminophylline level 48 hours after starting treatment was $8 \mathrm{mg} / \mathrm{l}$ (therapeutic range $6 \cdot 6-11 \mathrm{mg} / \mathrm{l}$. $11 \mathrm{mg} / \mathrm{l}$, Shannon et al., 1975).

24 hours after the introduction of aminophylline, capillary $\mathrm{PCO}_{2}$ had fallen to $5.3 \mathrm{kPa}(40 \mathrm{mmHg})$; there had been no change in the ventilator settings. The infant was then successfully weaned from the ventilator.

\section{Case 2}

This infant was also born at 30 weeks' gestation and weighed $1150 \mathrm{~g}$. At age 12 days he began to have episodes of apnoea and bradycardia. Capillary bloodgases at this stage showed a $\mathrm{PCO}_{2}$ of $8.9 \mathrm{kPa}(67 \mathrm{mmHg})$. Biochemical and infective causes for the apnoea were excluded while the chest $x$-ray was compatible with early chronic lung disease of prematurity. A loading dose of $3.8 \mathrm{mg} / \mathrm{kg}$ aminophylline was given intravenously followed by a maintenance dose of $3.1 \mathrm{mg} / \mathrm{kg}$ per day in three divided doses. Serum aminophylline level 48 hours after starting treatment was $6.5 \mathrm{mg} / \mathrm{l}$. 24 hours after the loading dose of aminophylline, the capillary $\mathbf{P C O}_{2}$ had fallen to $6.3 \mathrm{kPa}(47 \mathrm{mmHg})$ with no recurrence of the apnoea.

Our results support Barr's observations that aminophylline may be an aid in the weaning of infants from mechanical ventilation and, like caffeine (Aranda et al., 1977), will reduce the $\mathrm{PCO}_{2}$, probably by increasing the ventilatory effort and thereby increasing alveolar ventilation. 